\title{
Prevalence of Sensorineural Hearing Loss in Children with Palliated or Repaired Congenital Heart Disease
}

\author{
Lalitha Gopineti $^{1}$, Mane Paulpillai ${ }^{2}$, Andrea Rosenquist ${ }^{2}$, Andrew H. Van Bergen ${ }^{3}$ \\ 1. Pediatric Cardiology, Children's Mercy Hospitals and Clincs, Wichita, USA 2. Pediatric Cardiology, Advocate Christ \\ Medical Center, Oak Lawn, USA 3. Pediatric Cardiology, Advocate Children’s Hospital, Oak Lawn, USA
}

Corresponding author: Lalitha Gopineti, lalithagopineti@gmail.com

\section{Abstract \\ Background}

Children with congenital heart disease (CHD) are at increased risk of neurodevelopmental deficits, and the presence of sensorineural hearing loss (SNHL) may further lead to poor language skills acquisition and speech delays. Prevalence of SNHL in the general pediatric population is estimated to be $0.2 \%$ at birth to $0.35 \%$ during adolescence. Very few studies have attempted to estimate SNHL prevalence in children who have undergone congenital heart surgery.

\section{Methods}

This retrospective study aimed to estimate SNHL prevalence in children who underwent congenital heart surgery in our institution and were followed up in our high-risk pediatric cardiology clinics for four years from 2009 to 2013. Data were collected on demographics, preoperative variables, surgical variables, and post-operative variables.

\section{Results}

SNHL prevalence in asymptomatic, palliated/repaired CHD patients followed in our high-risk clinics and undergoing routine surveillance was $11.6 \%$ (20 of 172 patients with hearing impairment). SNHL prevalence was not statistically higher in single-ventricle patients (17.2\%) compared to biventricular patients (14.7\%). Inotropic score in the first 24 hours of postoperative period $(\mathrm{p}=0.05)$, lowest arterial $\mathrm{PaO} 2(\mathrm{p}=0.003)$, duration of Lasix drip $(\mathrm{p}=0)$, and bolus dose in days $(\mathrm{p}=0.03)$ were all found to be statistically significant in the hearing-impaired group. However, using logistic regression, we identified no statistically significant predictors for hearing loss.

\section{Conclusion}

Received 11/22/2019 Review began 11/25/2019 Review ended 12/30/2019 Published 01/04/2020

\section{() Copyright 2020}

Gopineti et al. This is an open access article distributed under the terms of the Creative Commons Attribution License CC-BY 3.0., which permits unrestricted use, distribution, and reproduction in any medium, provided the original author and source are credited.
The results suggest the need for routine audiology screening of all patients with complex CHD, especially those who have undergone neonatal cardiac repair/palliation at less than one year of age, irrespective of risk factors.

Categories: Cardiac/Thoracic/Vascular Surgery, Cardiology, Pediatrics

Keywords: hearing loss, prevalence, congenital heart disease

\section{Introduction}

Survival and life expectancy of children with congenital heart defects have dramatically increased in recent years due to advances in medical and surgical management strategies. Children with congenital heart disease (CHD) are at increased risk of neurodevelopmental deficits [1], and the presence of sensorineural hearing loss (SNHL) may further lead to poor language skills acquisition and speech delays [2]. The prevalence of SNHL in the general pediatric population is estimated to be $0.2 \%$ at birth to $0.35 \%$ during adolescence [3]. Many studies have estimated the prevalence of SNHL in the premature neonate population and have identified several associated risk factors [4]. One such study estimated the prevalence in neonates to be as high as $13.7 \%$ [5]. Very few studies, however, have attempted to estimate the prevalence of SNHL in children who have undergone congenital heart surgery. Of these studies, one old study estimated the prevalence to be $16 \%$ in CHD patients [6], and a recent study estimated the prevalence to be as high as $28.6 \%$ among childhood survivors after the Norwood/Sano operation only [7]. Currently, no clear recommendations exist for audiology screening in patients undergoing repair or palliation of CHD. The American Heart Association recommends audiology examination if there is no audiology examination since birth and if there is any suspicion of hearing impairment after cardiac surgery [8].

The first purpose of this study was to estimate the prevalence of SNHL in children who underwent 


\section{Cureus}

congenital heart surgery in our institution and were followed up in our high-risk pediatric cardiology clinics for four years, from 2009 to 2013. The prevalence of SNHL in single-ventricle (SV) patients was also compared to that in biventricular (BiV) patients. Another objective of this study was to identify all possible risk factors associated with SNHL in palliated CHD patients to assess the need for routine hearing screening in patients with complex CHD.

\section{Materials And Methods}

We performed a retrospective chart review of patients followed in our high-risk pediatric cardiology clinics from 2009 to 2013 who had routine audiology evaluations. The study design was approved by the institutional review board. Data were collected on patient demographics and preoperative variables such as prematurity and birth weight, presence of genetic syndromes, as well as surgical variables such as total cardiopulmonary bypass time, circulatory arrest time, and cross-clamp time (Table 1).

\begin{tabular}{|c|c|c|c|c|}
\hline \multirow{2}{*}{ Characteristic } & \multicolumn{2}{|l|}{ Hearing } & \multirow{2}{*}{ Z statistic } & \multirow{2}{*}{ P Value* } \\
\hline & Normal hearing $(n=125)$ & Hearing loss $(n=20)$ & & \\
\hline \multicolumn{5}{|l|}{ Sex } \\
\hline Male & $79(63.2 \%)$ & $15(75 \%)$ & -1.023 & 0.307 \\
\hline Female & $46(36.8 \%)$ & $5(25 \%)$ & & \\
\hline \multicolumn{5}{|l|}{ Prematurity } \\
\hline No & $110(88 \%)$ & $15(75 \%)$ & -1.560 & 0.119 \\
\hline Yes & $15(12 \%)$ & $5(25 \%)$ & & \\
\hline \multicolumn{5}{|l|}{ Diagnosis } \\
\hline Mild CHD & $7(5.6 \%)$ & 0 & -1.089 & 0.276 \\
\hline Moderate 2V CHD & $21(16.8 \%)$ & 0 & & \\
\hline Severe $2 \mathrm{~V}$ & $33(26.4 \%)$ & $9(45 \%)$ & & \\
\hline Palliated 1V & $64(51.2 \%)$ & $11(55 \%)$ & & \\
\hline \multicolumn{5}{|l|}{ Hearing loss status } \\
\hline Moderate/Severe/Profound loss & & $10(45 \%)$ & -11.967 & 0.000 \\
\hline Mild loss & & $11(55 \%)$ & & \\
\hline \multicolumn{5}{|l|}{ Hearing aids status } \\
\hline Yes & & $4(20 \%)$ & -11.563 & 0.000 \\
\hline No & & $16(80 \%)$ & & \\
\hline `Wilcoxon Mann-Whitney & & & & \\
\hline
\end{tabular}

\section{TABLE 1: Demographic characteristics of patients}

CHD: congenital heart disease.

Post-operative variables were also collected. These included lowest arterial $\mathrm{P}^{\mathrm{H}}$. and $\mathrm{PaO} 2$, exposure to known ototoxic medications such as furosemide, hydrochlorothiazide, gentamycin, and vancomycin and their cumulative doses in $\mathrm{mg} / \mathrm{kg}$ along with duration, inotropic scores in the first two postoperative days, need for extracorporeal membrane oxygenation (ECMO), and clinical seizures. Data collection was performed by a research assistant who was blinded to the hearing test results. Table 2 shows various diagnoses in the study patients. 


\section{Cureus}

\begin{tabular}{|l|l|}
\hline Diagnosis & Number of patients \\
\hline Arch anomaly (CoA, IAA) & 13 \\
\hline AS/sub AS & 3 \\
AVC/TOF & 12 \\
DILV & 6 \\
DORV & 8 \\
DTGA & 15 \\
Heterotaxy & 7 \\
HLHS & 44 \\
HRHS (PA/IVS, PA,VSD) & 18 \\
VSD & 7 \\
\hline Other (L-TGA, TAPVR, Sinus venosus ASD, Coronary anomalies, Truncus, Isolated MV disease) & 7 \\
\hline
\end{tabular}

\section{TABLE 2: Various diagnoses in the study patients}

CoA: coenzyme A; IAA: interrupted aortic arch; AS: aortic stenosis; DILV: double inlet left ventricle; DORV: double outlet right ventricle; DTGA: dtransposition of the great arteries; HLHS: hypoplastic left heart syndrome; PA: pulmonary atresia; IVS: intact ventricular septum; VSD: ventricular septal defect; L-TGA: levo-transposition of the great arteries; TAPVR: total anomalous pulmonary venous return; ASD: atrial septal defect; MV: mitral valve.

Exclusion criteria were any known genetic syndrome association with SNHL or family history of hearing loss, and any previously documented failed newborn screening. Drug dosages were calculated as cumulative doses in $\mathrm{mg} / \mathrm{kg}$ based on the weight at the time of each operation. Audiology assessment was performed by an experienced pediatric audiologist using age-appropriate and standard procedures. Young children and developmentally delayed children underwent visually reinforced audiometry, while older children underwent behavioral audiological assessment using pure tone audiometry. All children with test results indicating impaired hearing underwent auditory brain stem response for confirmation. Hearing loss was classified as mild when the hearing loss range in decibels $(\mathrm{dB})$ was $26-40 \mathrm{db}$. Hearing loss range in $\mathrm{dB}>40 \mathrm{~dB}$ was grouped as moderate to severe to profound loss [9]. Comparisons between normal and abnormal hearing groups were done using the $\mathrm{t}$ test. All collected data were de-identified and stored in a password-protected computer database. All statistical tests were run using Statistical Package for the Social Sciences (SPSS Inc., Chicago, IL).

\section{Results}

A total of 172 patients were identified, 20 of whom were found to have hearing impairment ranging from mild loss to moderate to severe to profound loss in one or both ears. No patient met the exclusion criteria. The prevalence of SNHL in asymptomatic; palliated/repaired CHD patients followed in our high-risk clinics undergoing routine surveillance was $11.6 \%$ (20 with hearing impairment out of 172 patients). The prevalence of SNHL was higher in SV patients (17.2\%) compared to BiV patients (14.7\%), but there was no statistically significant difference (odds ratio 1.16 , confidence interval: $0.45-3$ ) (Table 3). Twenty-seven out of 172 patients were eliminated from univariate analysis due to lack of records, as their surgeries were performed in a different institution. A total of 145 patients were reviewed for univariate analysis. Inotropic score in the first 24 hours of postoperative period $(\mathrm{p}=0.05)$, lowest arterial PaO2 $(\mathrm{p}=0.003)$, the duration of furosemide drip $(\mathrm{p}=0)$, and bolus doses in days $(\mathrm{p}=0.03)$ were found to be statistically different between the two groups (Table 4). However, using logistic regression, we identified no statistically significant predictors for hearing loss. 


\section{Cureus}

\begin{tabular}{|c|c|c|c|}
\hline & Hearing Loss & Normal Hearing & Prevalence \\
\hline SV Pts & 11 & 64 & $17.2 \%$ \\
\hline BiV Pts & 9 & 61 & $14.7 \%$ \\
\hline \multicolumn{4}{|c|}{ Odds Ratio 1.16; Cl 0.45-3 } \\
\hline$\angle$ statisti & 0.15 & & \\
\hline
\end{tabular}

TABLE 3: Prevalence of hearing loss in single-ventricle patients and biventricular patients SV: single-ventricle; BiV: biventricular; $\mathrm{Cl}$ : confidence interval 


\begin{tabular}{|c|c|c|c|c|c|c|c|c|c|c|}
\hline & \multicolumn{4}{|c|}{ Normal Hearing $(\mathrm{N}=125)$} & \multicolumn{4}{|c|}{ Hearing Loss $(\mathrm{N}=20)$} & \multirow[b]{2}{*}{ t Statistic } & \multirow[b]{2}{*}{$p$ value } \\
\hline & $\mathrm{N}$ & Mean & Median & Std. Deviation & $\mathrm{N}$ & Mean & Median & Std. Deviation & & \\
\hline Wks prematurity & 13 & 35.115 & 35.700 & 1.361 & 5 & 35.140 & 36.000 & 2.332 & -0.028 & 0.978 \\
\hline Birth Weight (Kg) & 112 & 3.123 & 3.100 & 0.643 & 18 & 2.872 & 2.910 & 0.545 & 1.566 & 0.120 \\
\hline No. Cardiac Surgeries & 125 & 2.272 & 2.000 & 1.058 & 20 & 2.450 & 2.000 & 0.887 & -0.810 & 0.425 \\
\hline CPB time (min) & 125 & 193.168 & 198.000 & 108.228 & 19 & 189.158 & 171.000 & 90.258 & 0.153 & 0.878 \\
\hline Arrest time (min) & 125 & 24.816 & 0.000 & 32.226 & 19 & 23.368 & 0.000 & 26.243 & 0.186 & 0.852 \\
\hline Aortic CC time (min) & 125 & 80.024 & 67.000 & 64.365 & 19 & 80.368 & 84.000 & 80.670 & -0.021 & 0.983 \\
\hline VIS24 & 125 & 20.012 & 18.000 & 14.166 & 19 & 26.732 & 30.000 & 15.169 & -1.909 & 0.058 \\
\hline VIS48 & 125 & 15.800 & 16.000 & 12.312 & 19 & 21.342 & 22.000 & 14.953 & -1.775 & 0.078 \\
\hline Lowest Arterial Ph & 120 & 7.241 & 7.250 & 0.097 & 19 & 7.196 & 7.220 & 0.095 & 1.867 & 0.064 \\
\hline Lowest Arterial PO2* & 120 & 37.825 & 30.000 & 20.017 & 19 & 29.421 & 26.000 & 8.681 & 3.109 & 0.003 \\
\hline Number of Ventilator days & 124 & 12.194 & 10.500 & 11.929 & 19 & 29.105 & 18.000 & 38.894 & -1.882 & 0.076 \\
\hline Cumulative Lasix drip dose (mg/kg) & 120 & 22.390 & 0.650 & 47.550 & 18 & 26.776 & 17.700 & 32.171 & 0.378 & 0.706 \\
\hline Total Lasix drip days* & 121 & 54.160 & 4.000 & 107.811 & 18 & 7.167 & 4.500 & 7.950 & 4.710 & 0.000 \\
\hline Cumulative Lasix Bolus dose (mg/kg) & 119 & 93.800 & 62.530 & 101.768 & 18 & 101.139 & 80.650 & 106.782 & 0.283 & 0.777 \\
\hline Total Lasix Bolus days* & 124 & 11.742 & 8.500 & 11.665 & 18 & 24.967 & 19.500 & 23.719 & -2.325 & 0.032 \\
\hline Cumulative Gentamycin dose (mgkg) & 124 & 24.887 & 3.500 & 55.672 & 18 & 57.037 & 17.785 & 84.953 & -1.558 & 0.136 \\
\hline Total Gentamycin days & 124 & 6.250 & 0.000 & 24.168 & 18 & 13.167 & 4.000 & 18.875 & -1.162 & 0.247 \\
\hline Cumulative Vancomycin dose (mgkg) & 124 & 264.223 & 0.000 & 624.629 & 18 & 394.130 & 28.500 & 677.284 & -0.816 & 0.416 \\
\hline Total Vancomycin days & 124 & 3.597 & 0.000 & 6.351 & 19 & 11.842 & 2.000 & 19.909 & -1.791 & 0.900 \\
\hline Cumulative Diuril dose (mgkg) & 123 & 59.427 & 8.240 & 241.799 & 18 & 28.444 & 11.400 & 40.366 & 0.541 & 0.589 \\
\hline Total Diuril days & 123 & 3.577 & 2.000 & 5.940 & 18 & 6.000 & 2.500 & 7.585 & -1.557 & 0.122 \\
\hline Total ECMO days & 125 & 0.280 & 0.000 & 1.3947 & 19 & 0.421 & 0.000 & 1.835 & -0.393 & 0.695 \\
\hline \multicolumn{11}{|c|}{ * Significant difference between groups t-test } \\
\hline & & & & & & & & & & \\
\hline
\end{tabular}

\section{TABLE 4: Univariate analyses}

CPB: cardiopulmonary bypass; ECMO: extracorporeal membrane oxygenation.

\section{Discussion}

In our high-risk cohort, we estimated the prevalence of hearing loss of $11.6 \%$, which is higher than in the general pediatric population as well as in neonatal intensive care unit (NICU) survivors (2\%-4\%) [10]. Limitations of the study include the small population size and the deficiency that not all patients underwent elective screening after congenital heart surgery. Only those patients followed up in high-risk pediatric cardiology clinics underwent the hearing test. Hence a true prevalence is not possible to calculate from the study. However, the study provides an estimate of prevalence which is higher than the prevalence of SNHL in the general pediatric population. This prevalence study did not examine all possible etiologies of SNHL like cytomegalovirus (CMV) infection, as no serologies were done to test for CMV infection due to this being a retrospective study. The biggest strength of this study is that the exposure to ototoxic medications was compared in the groups. The other advantage of our study is that it included all complexities of CHD, including mild CHD, moderate 2 ventricle, severe 2 ventricle, and palliated single ventricle, and could represent the estimated prevalence in repaired/palliated CHD in general.

Inner ear ischemia and hypo perfusion are the main proven physiological mechanisms for hearing loss after 
open heart surgery [11-12]. Hypoxia and bolus administration of furosemide have been reported to be significant risk factors for hearing loss in children after cardiopulmonary bypass surgery [7]. The duration of ECMO therapy and clinical seizure activity prior to ECMO are independently associated with SNHL [13].

\section{Conclusions}

Our study supports the previously proven etiologies of hypoxia and longer duration of furosemide as strongly associated with SNHL. However, using logistic regression, we identified no single independent predictor as statistically significant for causing hearing loss in complex CHD. But because of the high prevalence of SNHL in this group, the results suggest the need for routine audiology screening of all patients with complex $\mathrm{CHD}$, especially in patients who have undergone neonatal cardiac repair as well as palliation below one year of age, irrespective of risk factors. This screening is necessary to identify children at risk and intervene before SNHL negatively affects their neurodevelopment.

\section{Additional Information \\ Disclosures}

Human subjects: All authors have confirmed that this study did not involve human participants or tissue. Animal subjects: All authors have confirmed that this study did not involve animal subjects or tissue. Conflicts of interest: In compliance with the ICMJE uniform disclosure form, all authors declare the following: Payment/services info: All authors have declared that no financial support was received from any organization for the submitted work. Financial relationships: All authors have declared that they have no financial relationships at present or within the previous three years with any organizations that might have an interest in the submitted work. Other relationships: All authors have declared that there are no other relationships or activities that could appear to have influenced the submitted work.

\section{References}

1. Sananes R, Manlhiot C, Kelly E, et al.: Neurodevelopmental outcomes after open heart operations before 3 months of age. Ann Thorac Surg. 2012, 93:1577-1583. 10.1016/j.athoracsur.2012.02.011

2. Morzaria S, Westerberg BD, Kozak FK: Systematic review of the etiology of bilateral sensorineural hearing loss in children. Int J Pediatr Otorhinolaryngol. 2004, 68:1193-1198. 10.1016/j.ijporl.2004.04.013

3. Deltenre P, Van Maldergem L: Hearing loss and deafness in the pediatric population: causes, diagnosis, and rehabilitation. Handb Clin Neurol. 2013, 113:1527-1538. 10.1016/B978-0-444-59565-2.00023-X

4. Coenraad S, Goedegebure A, van Goudoever JB, Hoeve LJ: Risk factors for sensorineural hearing loss in NICU infants compared to normal hearing NICU controls. Int J Pediatr Otorhinolaryngol. 2010, 74:999-1002. 10.1016/j.ijporl.2010.05.024

5. Pourarian S, Khademi B, Pishva N, Jamali A: Prevalence of hearing loss in newborns admitted to neonatal intensive care unit. Iran J Otorhinolaryngol. 2012, 24:129-134.

6. Arnold SA, Brown OE, Finitzo T: Hearing loss in children with congenital heart disease: a preliminary report. Int J Pediatr Otorhinolaryngol. 1986, 11:287-293. 10.1016/s0165-5876(86)80041-6

7. Robertson CM, Alton GY, Bork KT, et. al: Bilateral sensory permanent hearing loss after palliative hypoplastic left heart syndrome operation. Ann Thorac Surg. 2012, 93:1248-1253. 10.1016/j.athoracsur.2011.08.042

8. Marino BS, Lipkin PH, Newburger JW, et. al: Neurodevelopmental outcomes in children with congenital heart disease: evaluation and management. Circulation. 2012, 126:1143-1172. 10.1161/CIR.0b013e318265ee8a

9. Clark JG: Uses and abuses of hearing loss classification. Asha. 1981, 23:493-500.

10. Joint Committee on Infant Hearing: Year 2007 position statement: principles and guidelines for early hearing detection and intervention programs. Pediatrics. 2007, 120:898-921. 10.1542/peds.2007-2333

11. Arenberg IK, Allen GW, Deboer A: Sudden deafness immediately following cardiopulmonary bypass. J Laryngol Otol. 1972, 86:73-77. 10.1017/s0022215100074946

12. Shapiro MJ, Purn JM, Raskin C: A study of the effects of cardiopulmonary bypass surgery on auditory function. Laryngoscope. 1981, 91:2046-2052. 10.1288/00005537-198112000-00007

13. Murray M, Nield T, Larson-Tuttle C, Seri I, Friedlich P: Sensorineural hearing loss at 9-13 years of age in children with a history of neonatal extracorporeal membrane oxygenation. Arch Dis Child Fetal Neonatal Ed. 2011, 96:F128-F132. 10.1136/adc.2010.186395 